
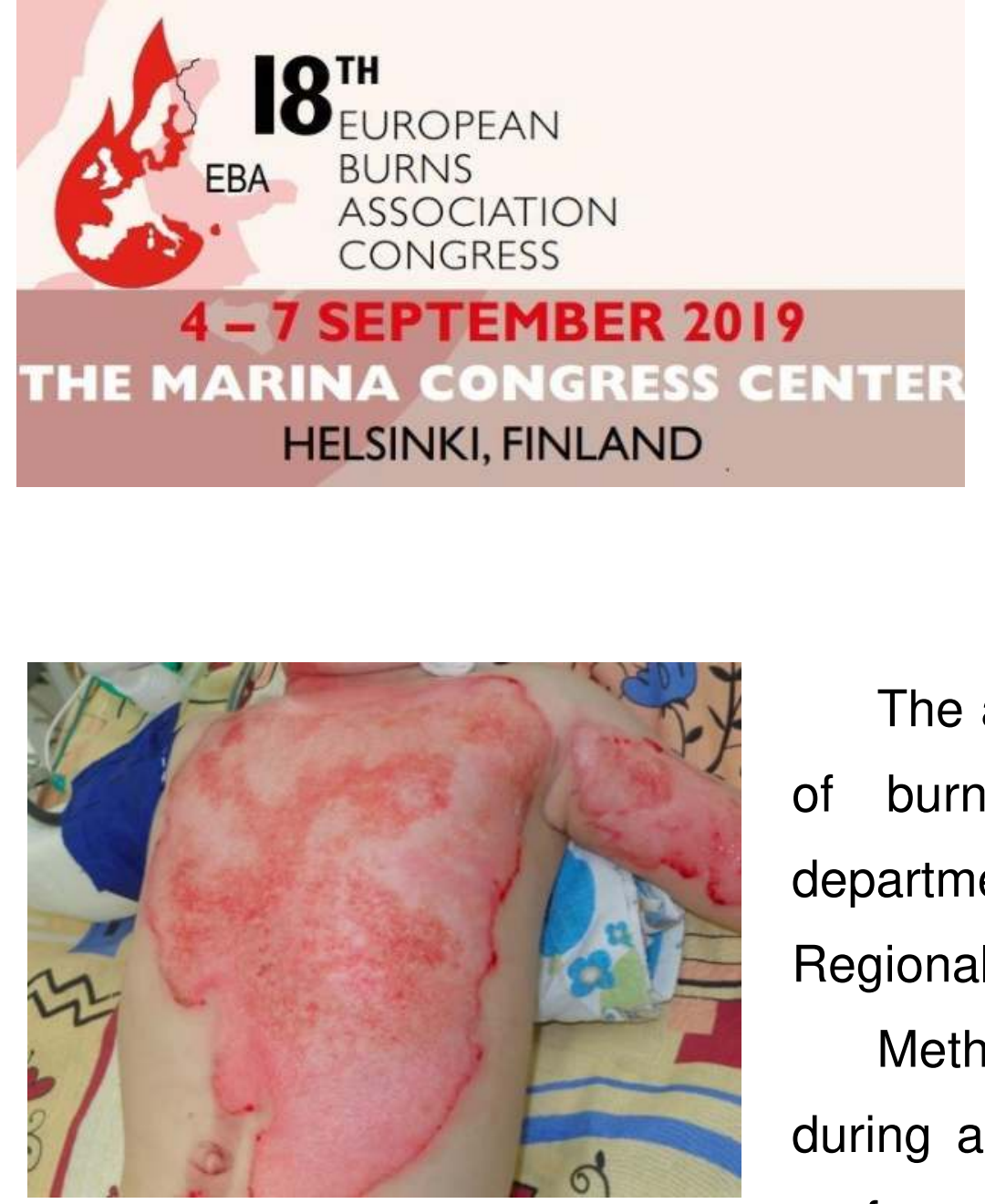

Fig. 1. Two days after trauma

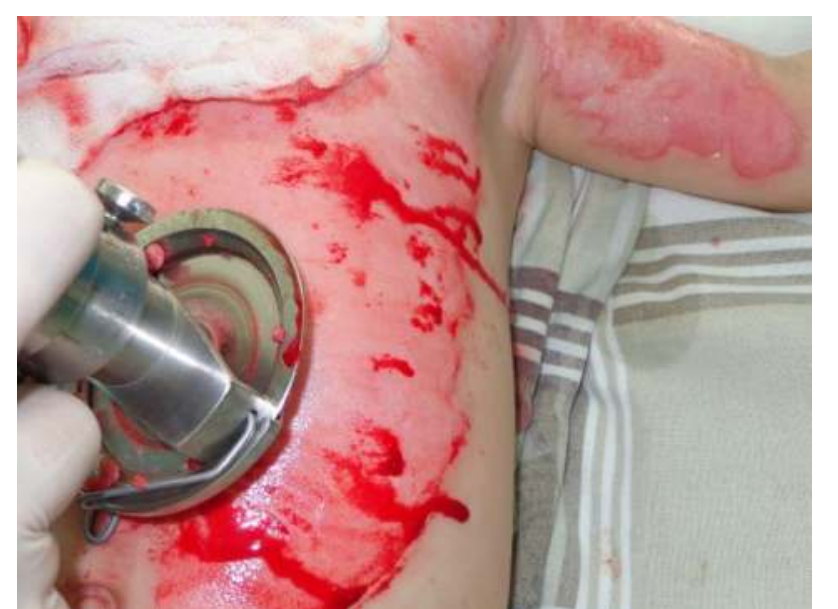

Fig. 2. Necrectomy is performed

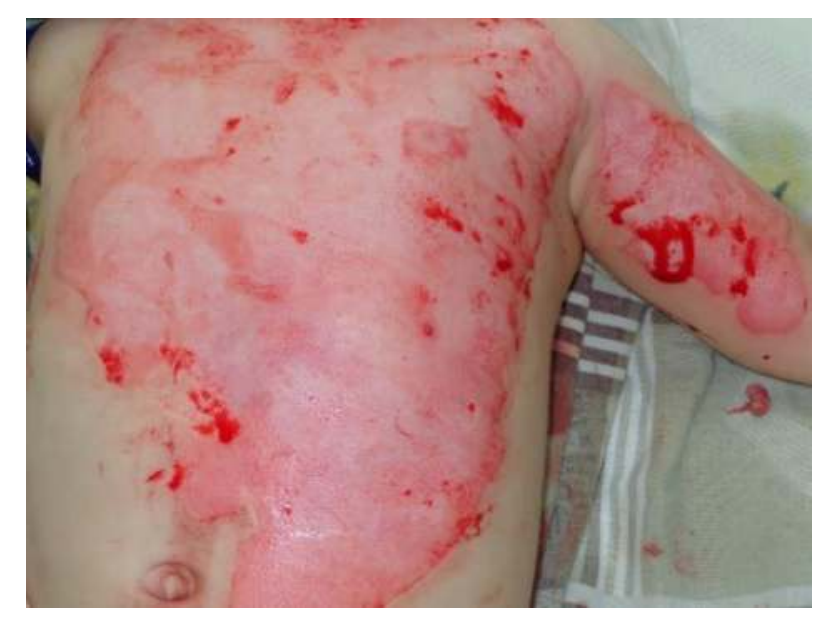

Fig. 3. After hemostasis

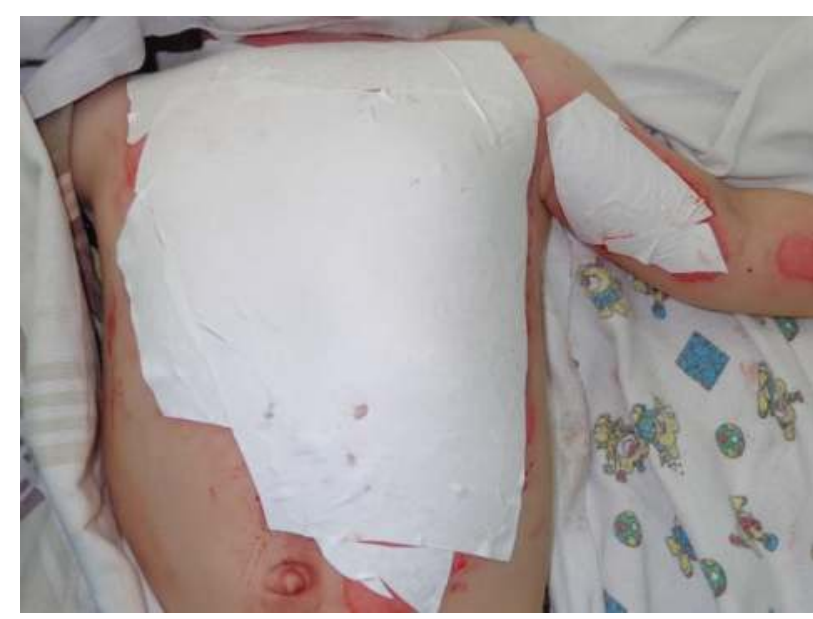

Fig. 4. Wound coating Suprathel is applied

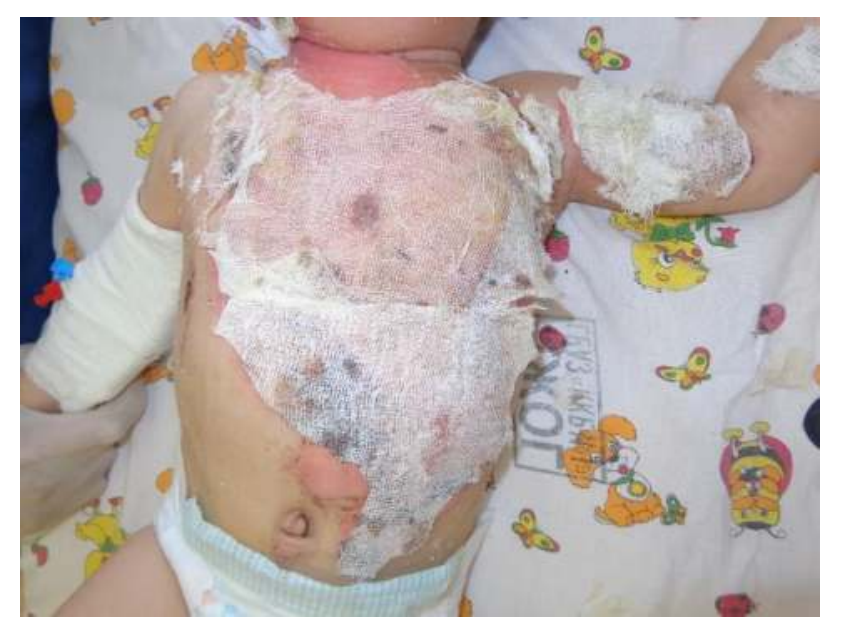

Fig. 5. The first change of bandages in 5 days dressings.

\section{THE USING OF WOUND COVERINGS IN SURGICAL TREATMENT OF BURNS IN REGIONAL BURN CENTRE}

\author{
Bogdanov S.B., Poliakov A.V.
}

The aim of our study was to analyze the results of treatment of burn patients using «Suprathel» in Krasnodar burn department of Scientific Research Institute - Ochapovsky Regional Clinical Hospital №1.

Methods. We use early surgical treatment of burnt patients during about 25 years. Patients with deep dermal burns were performed necrectomy in 2-5 days after injury. After necrectomy we used skin graft plasty and wound dressing. In order to create optimal conditions for the epithelialization of deep dermal burns after necrectomy we applied «Suprathel» since 2015. After necrectomy to the lower layers of the dermis we used napkins with epinephrine hemostasis for 5-7 minutes. Then superimposed sterile wound covering "Suprathel», which is fixed with a bandage.

Results. Subsequently, only cosmetic dressings performed starting from the third day after surgery. Wound coatings were not removed until complete epithelialization of wounds. Epithelialization occurs depending on the depth of burns 8-12 days after surgery. When staged surgical treatment of painful dressings with ointments, without «Suprathel», made every other day for 15-21 days.

Conclusion. In the traditional surgical treatment of deep dermal burns tend to deepen with the formation of granulation tissue and the need to follow skin graft plasty. A more preferred method of treatment of deep burns is a method of early surgical treatment, in which the skin necrosis is removed in the early stages after the burn, and the wound is closed wound coverings. We got faster wound epithelization with the use of «Suprathel» with large areas of burns. Research result has been an advantage once the surgical treatment of wounds using «Suprathel» to the local conservative treatment with long-lasting

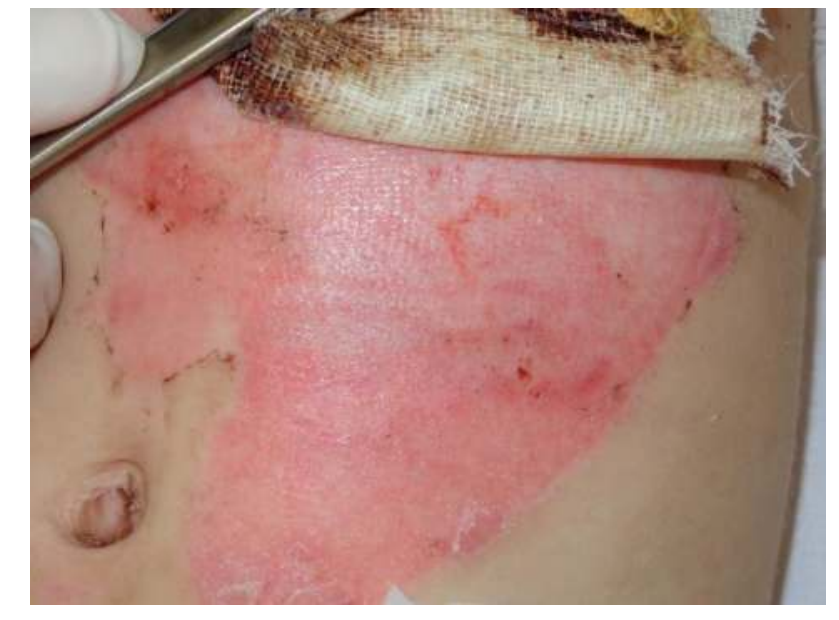

Fig. 6. Removal of bandages in 9 days after operation

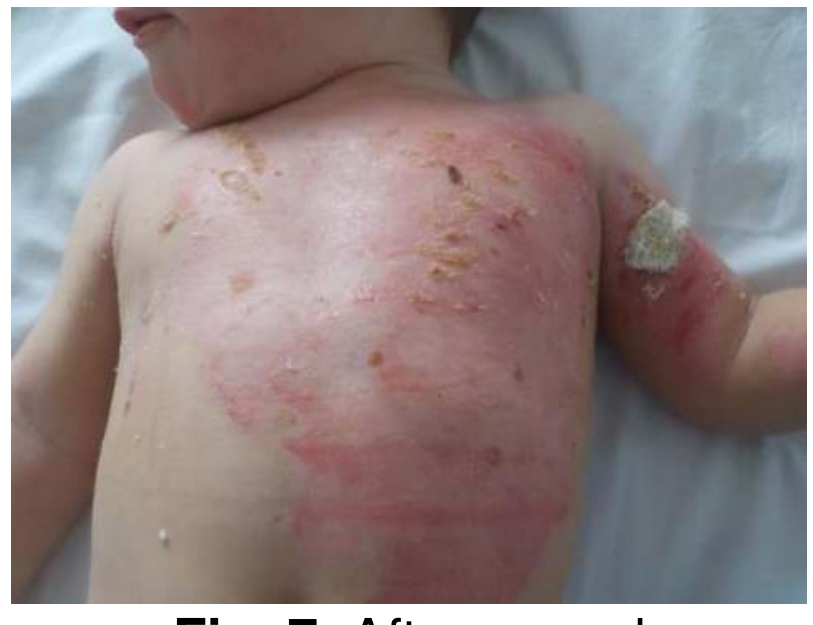

Fig. 7. After wound epithelialization

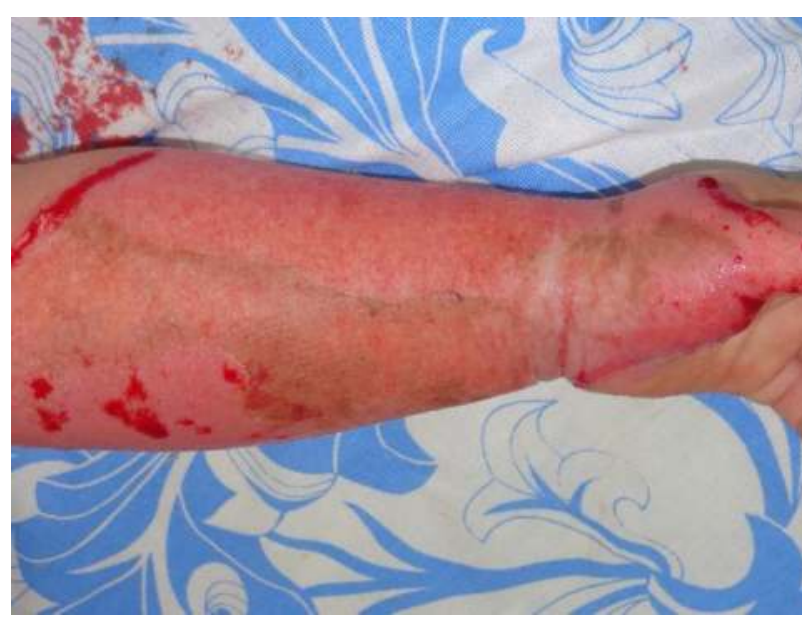

Fig. 8. Three days after trauma

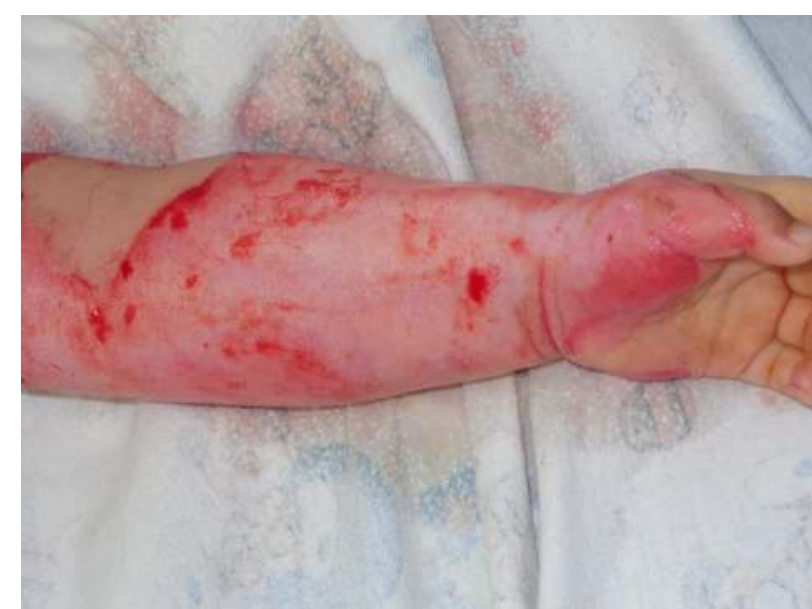

Fig. 9. After necrectomy

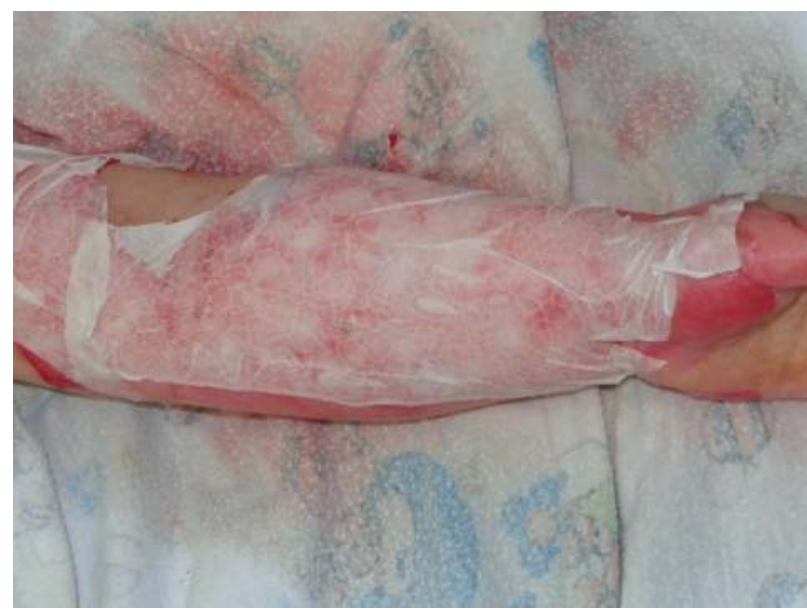

Fig. 10. Wound coating Suprathel is applied

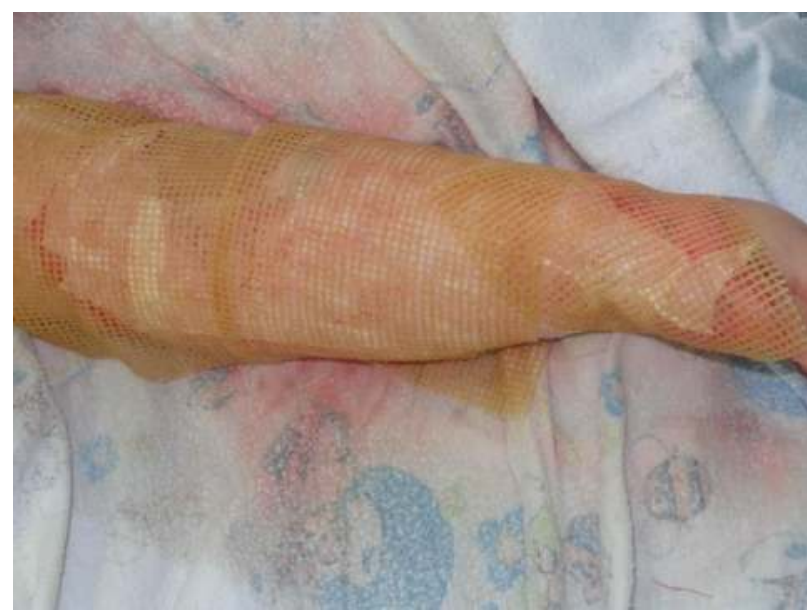

Fig. 11. Mesh coating is applied on top

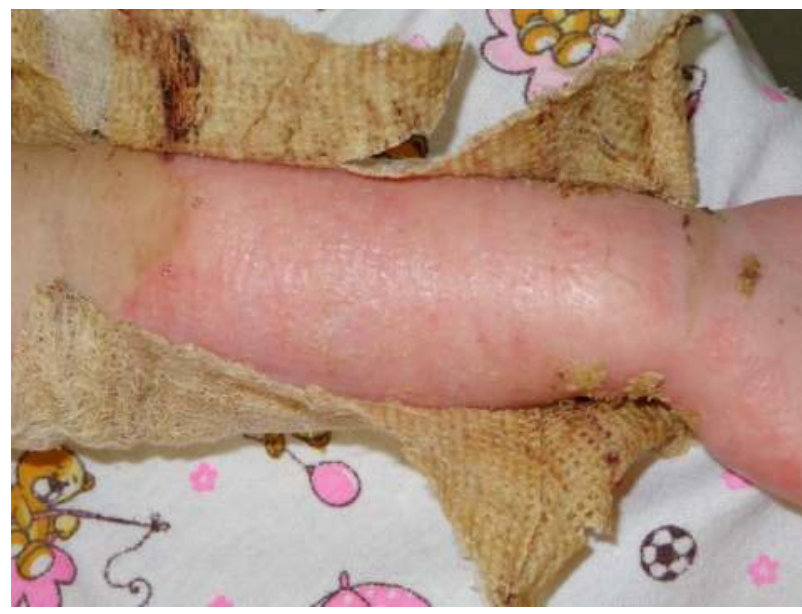

Fig. 12. Removal of bandages in 10 days after operation

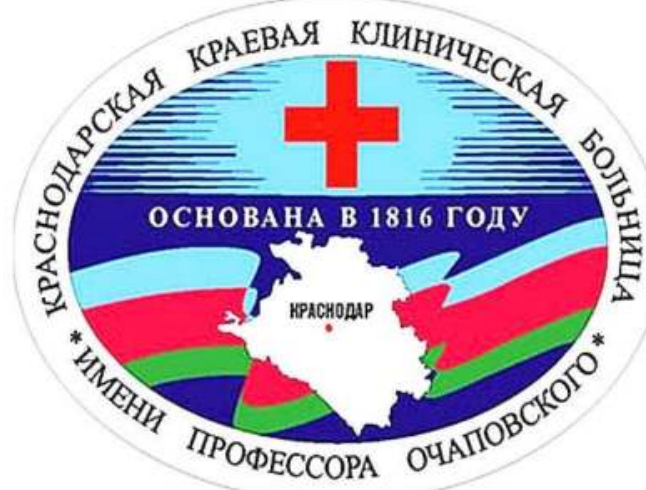

Scientific Research Institute Ochapovsky Regional Clinical Hospital №1 Krasnodar. Russian Federation

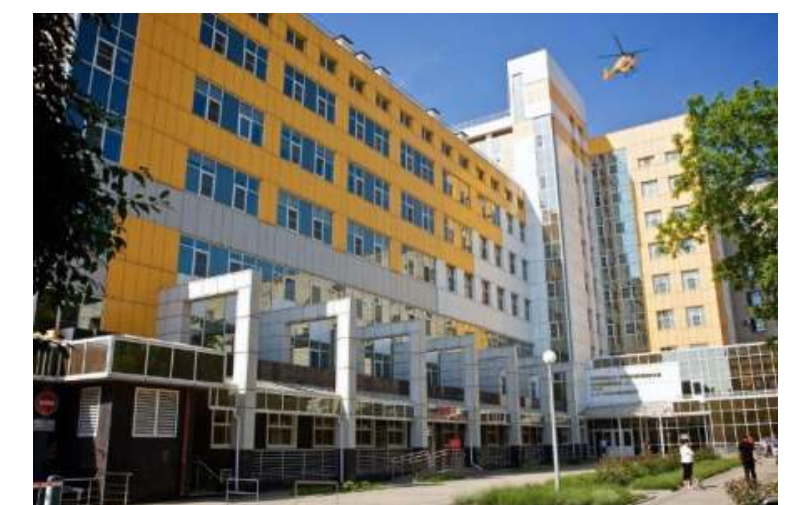

